\title{
ANALISA LAPORAN DANA BOS PADA SMTK LUKS CORNELLIA KOTA SORONG
}

\author{
Sri Hartatik, SE \\ Jurusan Akuntansi Keuangan Publik \\ Program Studi Diploma IV Akuntansi
}

\begin{abstract}
ABSTRAK
Pendidikan merupakan hal yang penting agar di masa mendatang sumber daya manusia dapat bersaing dalam persaingan yang semakin ketat dalam berbagi bidang kehidupan.Untuk itu pemerntah mengeluarkan kebijakan program Bantuan Operasional Sekolah (BOS). Program ini diharapkan dapat menguragi beban peserta didik Agar tercapainya program kebijakan dana bantuan operasional sekolah tersebut maka pemerintah memberikan Buku Petunjuk Dana BOS Agar sekolah dapat menggunakan buku petunjuk yang telah disedikan sebagai petunjuk perencanaan, penggunaan realisasi dana BOS dan Pengisian buku kas umum sekolah sebagaimana mestinya. Agar nanti nya tidak terjadi kesalahan kesalahan dalam pencatatan penggunaan dana BOS.
\end{abstract}

\section{PEDAHULUAN}

\subsection{Latar Belakang}

Program wajib belajar pendidikan dasar 9 tahun yang dicanangkan sejak 2 mei 1994 merupakan usaha pemerintah untuk meningkatkan kualitas serta mempermudah akses pendidikan di Indonesia. Program wajib belajar 9 tahun ini tercapai dengan menciptakan program Bantuan Operasional Sekolah (BOS) pada tahun 2005. Seiring berjalannya waktu, mulai tahun 2009 pemerintah telah melakukan perubahan tujuan, pendekatan, dan orientasi-program BOS. Program BOS bukan hanya berperan untuk mempertahankan jumlah peserta didik saja, namun juga harus berkontribusi dalam peningkatan mutu pendidikan.

Selain itu kenaikan jumlah dana BOS yang signifikan mulai tahun 2009 diharapkan akan menjadikan BOS sebagai pilar utama mewujudkan pendidikan tanpa dipungut biaya. Program wajib belajar 9 tahun tersebut berhasil meningkatkan angka partisapasi kasar dalam pendidikan tingkat dasar. Tuntasnya program wajib belajar 9 tahun ini antara lain diukur melalui tambahnya jumlah gedung dan ruang kelas baru di dekat masyarakat yang banyak memiliki anak-anak wajib belajar (usia 7-15 tahun), memperluas kejar jangkauan SMP terbuka dan menambah Tempat Kegiatan Belajar (TKB) dan paket b, serta meningkatnya peran dan kesadaran masyarakat dalam pelaksanaan wajib belajar.

Keberhasilan program wajib belajar 9 tahun menjadikan lulusan SMP semakin meningkat, sehingga pemerintah menambah daya tampung layanan pendidikan menengah (SMA dan SMK) untuk menampung para siswa memperoleh jenjang pendidikan yang lebih tinggi. Kementerian Pendidikan dan Kebudayaan telah meluncurkan kebijakan Pendidikan Menengah Universal (PMU) yang implementasinya difokuskan untuk memberikan kesempatan kepada seluruh masyarakat. Tujuan utama program tersebut adalah anggota masyarakat yang secara ekonomi tidak mampu memenuhi biaya operasional sekolah, juga memberikan layanan pendidikan terjangkau dan bermutu terutama bagi siswa miskin.

Rencana strategis KEMENDIKBUD 20102014 menjabarkan bahwa implementasi PMU difokuskan pada peningkatan layanan peserta didik dengan pemberian Bantuan Operasional Sekolah Menegah (BOS SM); penyediaan daya tampung pendidikan menengah melalui pembangunan Unit Sekolah Baru (USB), Ruang Kelas Baru (RKB) dan rehabilitasi gedung sekolah; penyediaan dan peningkatan kualitas guru melalui peningkatan kerjasama dengan Lembaga Pendidikan Tenaga Kependidikan (LPTK) atau Perguruan Tinggi (PT) dalam penyediaan guru produktif dan pengusulan pengangkatan guru sekolah menengah; peningkatan kualitas pembelajaran melalui implementasi kurikulum 2013 yaitu dengan meningkatkan kompetensi peserta didik. Pemerintah secara umum memberikan dana BOS SMA untuk mewujudkan layanan pendidikan 
yang terjangkau dan bermutu bagi semua lapisan masyarakat.

Adanya bantuan yang diberikan pemerintah supaya sekolah membebaskan biaya pendidikan ataupun meringankan tagihan biaya sekolah, dan juga supaya kualitas proses pembelajaran di sekolah akan menjadi semakin meningkat. Besaran dana tahun 2014 yang diterima tiap sekolah dihitung berdasarkan jumlah siswa per sekolah dan satuan dana BOS SMA. Waktu penyaluran dana BOS sma ini diberikan ke sekolah persemester. Pengelolaan dana BOS wajib berpedoman pada petunjuk teknis BOS SMA yang diterbitkan oleh direktorat pembinaan SMA, sebagai teknis yang bertanggung jawab dalam pelaksanaan dan pengelolaan dana bos sma.

Salah satu faktor yang mempengaruhi keberhasilan program BOS adalah pengelolaan dana dan segala sumberdaya yang ada dalam program BOS. Pentingnya pengelolaan dana BOS SMA yaitu, dengan pengelolaan yang baik akan mampu membantu ketercapaian tujuan dari program BOS SMA dengan efektif dan efisien. Sekolah menempati posisi penting dalam penentuan penggunaan dana BOS SMA, karena sekolah merupakan instasi yang terkait langsung pengelolaan dana BOS. Kesalahpamahaman oleh pengelola dapat menimbulkan hambatan dalam pelaksanaan pengelolaan dana BOS sma. Kurang spesifiknya petunjuk yang ada dalam petunjuk teknis BOS sma menimbulkan penerjemahan yang berbeda-beda oleh pihak pengelola dana BOS SMA.

Hal ini menjadi permasalahan dan dapat menimbulkan dugaan adanya ketidaksesuaian dalam pertanggungjawaban laporan dana BOS dan buku petunjuk teknis penggunaan dan pertanggungjawaban keuangan dana bantuan operasional sekolah tahun 2017. Berdasarkan permasalahan,yang diuraikan di atas, peneliti bermaksud melaksanakan penelitian dengan judul "Analisa Laporan Dana BOS Pada Yayasan (SMTK) Sekolah Menengah Teologi Luks Cornellia Kota Sorong”.

\section{TINJAUAN PUSTAKA}

\subsection{Pengetian Laporan Keuangan}

Laporan keuangan adalah penyusunan laporan yang dilakukan setelah selesainya proses pencatatan, penggolongan dan peringkasan transaksi keuangan dalam suatu periode tertentu dan umumnya disusun setahun sekali.

\subsection{Pengertian Dana}

Umumnya, organisasi pemerintahan mengamgambil keputusan tentang sumber keuangan dan penggunaannya dikaitkan dengan tujuan politik dan sosial. Undang-undang peraturan lainnya memberikan batasan hukum aktivitas pemerintah. Ada dua jenis batasan hukum dan administrasi yang ditekankan dalam proses akuntansi dan pelaporan keuangan organisasi pemerintahan salah satunya yaitu, penggunaan dana.

\subsection{Pengertian Biaya Satuan Pendidikan}

Dana yang dibentuk oleh suatu unit pemerintah negara bagian atau pemerintah lokal untuk mempertanggungjawabkan semua aktifitas pemerintah umum yang tidak di pertanggungjawabkan dalam dana lain. Dari sepuluh jenis-jenis dana diatas yang dipertanggungjawabkan dalam bidang pendidikan adalah dana umum, dimana dana yang digunakan untuk mempertanggungjawabkan semua aktifitas layanan kepala sekolah-sekolah yang bersifat rutin.

\subsection{Pengertian Bantuan Operasional Sekolah}

Program Bantuan Operasional Sekolah (BOS) adalah program pemerintah yang pada dasarnya untuk penyediaan pendanaan biaya operasi nonpersonalia bagi satuan pendidikan dasar sebagai pelaksana program wajib belajar. Berdasarkan pentunjuk teknis BOS SMA tahun 2014, BOS SMA adalah program pemerintah berupa pemberian dana langsung kepada SMA negeri dan swasta untuk membantu memenuhi dana operasional non-personalia sekolah. (Dirjen Pendidikan Menengah Tentang Petunjuk Teknik BOS SMA Tahun 2014, 2014: 3).

\subsubsection{Kegunaan Dana Bantuan Operasional Sekolah}

Secara umum program BOS bertujuan untuk meringgankan beban masyarakat terhadap pembiayaan pendidikan dalam rangka memberikan pendidikan yang bermutu bagi 
sekolah sekolah SD/SMP dan SMA maupun sederajatnya. Selain dari pada itu, diharapkan program BOS juga dapat ikut berperan dalam pempercepat pencapaian standar pelayanan minimal sekolah.

\subsection{Penggunaan Dana BOS}

Penggunaan dana BOS di sekolah harus didasarkan pada kesepakatan dan keputusan bersama antara tim manejemen BOS sekolah, dewan guru, dan komite sekolah, yang harus didaftar sebagai salah satu sumber penerimaan dalam rencana Kegiatan Anggaran Sekolah (RKAS) atau Rencana Anggaran Pendapatan Dan Belanja Sekolah (RAPBS) atau sumber lain yang sah. Hasil kesepakatan penggunaan dana BOS (dan dana lainnya tersebut) harus dituangkan secara tertulis dalam bentuk berita acara rapat yang dilampirkan tanda tangan seluruh peserta rapat yang hadir. Dari seluruh dana BOS yang diterima, sekolah wajib menggunakan sebagian dana tersebut untuk membeli buku teks pelajaran atau mengganti yang telah rusak. Dan buku mata pelajaran lainya seperti agama, mata pelajaran seni budaya dan keterampilan, sejarah, ilmu pengetahuan sosial dan mata pelajaran teknologi informasi dan komonikasi.

\subsection{Pertanggungjawaban Keuangan}

Penggunaan dana BOS sepenuhnya menjadi tanggungjawab lembaga yang kegiatannya memcakup pencatatan penerimaan dan pengeluaran uang serta laporan keuangan, sehingga memudahkan proses pengawasan atas penggunaan dana.

\section{METODE PENELITIAN}

\subsection{Tempat Dan Objek Penelitian}

Penelitian dilakukan pada yayasan SMTK Luks Cornellia Kota Sorong Papua Barat yang beralamat pada Km 13 belakang UT(Unite Tractor) Jl. Trent. Penulis melakukan penelitian dua bulan dari bulan februari sampai dengan bulan maret tahun 2017

\subsection{Jenis Penelitian}

Penelitian ini merupakan penelitian kuantitatif karena data penelitian ini berupa laporan dana BOS dengan menggunakan buku petunjuk teknis penggunaan dan pertanggungjawaban keuangan dana bantuan operasional sekolah tahun 2017 berdasarkan peraturan menteri pendidikan dan Kebudayaan Republik Indonesia Nomor 8 tahun 2017.

\subsection{Jenis Dan Sumber Data}

Jenis data yang dipergunakan dalam penelitian ini adalah:

1. Kuantitatif

Yaitu seperti informasi biaya - biaya, peraturan peraturan dan data - data yang berhubungan dengan permasalahan yang akan dibahas.

2. Kualitatif

Yaitu data yang diperoleh dari objek penelitian dalam bentuk informasi mengenai struktur organisasi, pembagian tugas, dan lain - lainnya sumber data yang digunakan dalam penelitian ini.

Sumber data yang digunakan dalam dalam penelitian ini adalah :

a. Data primer

Yaitu data yang dikumpulkan sendiri oleh peneliti dari objek penelitian. Data ini diperoleh dari observasi, wawancara dan konsultasi terhadap pihak - pihak yang bersangkutan.

b. Data sekunder

Yaitu data yang diperoleh dari sumber sumber tertentu berupa data keuangan serta data pendukung lainnya yang berkaitan dengan masalah yang akan dibahas dalam penulisan ini.

\subsection{Metode Pengumpulan Data}

Metode pengumpulan data yang dilakukan dalam penelitian ini adalah

1. Metode observasi

2. Metode wawancara

3.Studi pustaka

\subsection{Teknik Analisis}

Teknik analisis yang dilakukan dalam penelitian ini adalah teknis analisis dengan menggunakan laporan keuangan dana BOS pada SMTK Luks Cornellia dan Buku Petunjuk Teknis Penggunaan Dan Pertanggungjawaban Keuangan Dana Bantuan Sekolah Tahun 2017 berdasarkan 
peraturan Menteri Pendidikan dan Kebudayaan Republik Indonesia Nomor 8 Tahun 2017.

\section{HASIL DAN PEMBAHASAN \\ 4.1 Hasil}

SMTK Luks Cornellia Kornellia Kota Sorong adalah sekolah yayasan yang bergerak, dalam bidang pendidikan. Sekolah ini didirikan pada tahun 2006 sampai sekarang. Dalam meningkatkan kualitas serta mempermudah akses pendidikan di Indonesia maka pemerintah pun menciptakan Program Bantuan Operasional Sekolah. Tujuan utama dari program bantuan operasional adalah agar anggota masyarakat yang secara ekonomi tidak mampu bisa memenuhi biaya operasional sekolah,

\subsection{Pembahasan}

Rencana penggunaan dana bantuan operasional sekolah yang akan digunakan untuk periode juli 2016 - september 2016. Besarnya jumlah perencanaan dana bantuan operasional sekolah diterima berdasarkan banyaknya jumlah peserta didik. Jumlah yang dianggarkan akan diterima.

Tabel 4.1

Rencana Penggunaan Dana BOS

Periode Juli 2016-September 2016

\begin{tabular}{|c|l|c|}
\hline No & \multicolumn{1}{|c|}{ Komponen } & $\begin{array}{c}\text { Jumlah dana } \\
(\mathbf{R p})\end{array}$ \\
\hline 1 & $\begin{array}{l}\text { Transport 17 guru, juli, agustus, september 2016 per bulan } \\
\text { @ Rp.625.000 }\end{array}$ & Rp30.000.000 \\
\hline 2 & $\begin{array}{l}\text { Bimbingan belajar (bimbel) 5 orang guru perperiode } \\
\text { agustus-september 2016 @ Rp. 1.000.000 }\end{array}$ & Rp 5.000.000 \\
\hline 3 & ATK untuk bulan juli, agustus, september 2016 & Rp15.000.000 \\
\hline 4 & Komsumsi untuk guru (juli, agustus, september 2016) & Rp 4.000.000 \\
\hline 5 & Penerimaan siswa baru & Rp 5.000.000 \\
\hline 6 & Transport panitia penerimaan siswa baru & Rp 5.000.000 \\
\hline 7 & Sarana dan prasarana sekolah & Rp 68.400.000 \\
\hline \multicolumn{2}{|c|}{ Jumlah } \\
\hline \multicolumn{2}{|c|}{ Terbilang :Enam Puluh Delapan Juta Empat Ratus Ribu Rupiah } \\
\hline
\end{tabular}

Sumber Data : Smtk Luks Cornellia

Berdasarkan tabel diatas SMTK miliki perencanaan pengeluaran sebesar Rp68.400.000,00 yang nantinya digunakan untuk transportasi guru, bimbingan belajar, belaja ATK, konsumsi, penerimaan siswa baru, transport panitia penerimaan siswa baru, dan sarana dan prasarana. 
Tabel 4.2

Pelaporan Rencana Anggaran Pendapatan Dan Belanja Sekolah (RAPBS)

Tahun Ajaran 2016

Nama

Sekolah

\begin{tabular}{|c|}
\hline Format BOS-KI \\
\hline Diisi Oleh Sekolah \\
Dikirim ke Tim Manejemen Bos \\
KabKota
\end{tabular}

\begin{tabular}{|c|c|c|c|c|c|c|c|}
\hline \multicolumn{4}{|c|}{ PENERIMAAH } & \multicolumn{4}{|c|}{ PEHGELUARAH BELAHJA } \\
\hline $\begin{array}{l}\text { No. } \\
\text { Urat }\end{array}$ & $\begin{array}{l}\text { Ho } \\
\text { Kode }\end{array}$ & Uraias & Julal & $\begin{array}{l}\text { Mo. } \\
\text { Urat }\end{array}$ & $\begin{array}{c}\text { Ho } \\
\text { Kode }\end{array}$ & Uraias & Jalala \\
\hline 1 & 2 & 3 & 4 & 5 & 6 & 7 & 8 \\
\hline $\mathbf{I}$ & $\mathbf{I}$ & SISA TAHUH LALU & 0 & $\mathbf{I}$ & $\begin{array}{c}\mathbf{I} \\
1.1\end{array}$ & $\begin{array}{l}\text { PROGRAH SEKOLAH } \\
\text { Psng. Troneportssi guru }\end{array}$ & $R_{p} 30.000 .000$ \\
\hline \multirow[t]{7}{*}{ II } & 2 & PENDAPATAK RUTIK & & & 1.2 & Peng. Proses Pembelsjorsh & Rp. 5.000 .000 \\
\hline & 2.1 & Goji PNS & & & 1.3 & Peng.ATK Sckolsh & Rp. 15.000 .000 \\
\hline & 2.2 & Gsji Psgswsi tidsk tctsp & & & 1.4 & Peng. Ssrons dan Prosesrsns Sckolsh & Rp. 5.000 .000 \\
\hline & 2.3 & Belonip Borsong don joss & & & 1.5 & Peng. Kegistsn Penerimosn peserto didik boru & Rp. 9.000 .000 \\
\hline & 2.4 & Beslonip Borsong don joss & & & & & \\
\hline & 2.5 & Pemclihsrson & & & & & \\
\hline & & Belonij Lvin-lsin & & & & & \\
\hline \multirow[t]{5}{*}{ III } & 3 & BAKTUAH OPERASIOHAL SEKOLAH & & & & & \\
\hline & 3.1 & Bos Puest & Rp. 68.400 .000 & & & & \\
\hline & 3.2 & Bos provingi & & & & & \\
\hline & 3.3 & BoS Ksbupsten Kots & & II & 2 & MOH PROGRAM SEKOLAH & \\
\hline & & 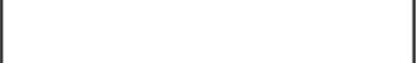 & & & 2.1 & Belsnip Bsrsng don Jses & RP. 4.400 .000 \\
\hline \multirow[t]{6}{*}{ IY } & 4 & BAKTUAN & & & & & \\
\hline & 4.1 & Dono Dekonsentrosi & & & & & \\
\hline & 4.2 & Dons Tugse Pembsntusn & & & & & \\
\hline & 4.3 & Dons Alokssi Khusus & & & & & \\
\hline & 4.4 & Lsin-Isin(Bsntusn lusr neggerilhibsh)" & & & & & \\
\hline & 5 & PEHDAPATAH ASLI SEKOLAH & & & & & \\
\hline \multicolumn{3}{|r|}{ Jualab Peneriesan } & Rp. 68.400 .000 & & & Juelab Pengelearan & Re. 68.400 .000 \\
\hline
\end{tabular}

$\overline{\text { Sumber :Buku Dana BOS }}$

Rencana Kegiatan dan Anggaran Sekolah atau Rencana Anggaran Rencana Kegiatan dan Anggaran Sekolah (RKAS) atau Rencana Anggaran Pendapatan Dan Belanja Sekolah (RAPBS) harus memuat rencana penerimaan dan rencana penggunaan uang dari semua sumber dana yang diteriama sekolah. RKAS atau RAPBS ditandatangani oleh Kepala Sekolah, Komite Sekolah dan khusus untuk swasta ketua yayasan. Dokumen ini disimpan disekolah dan di tunjukan kepada pengawas, tim manejemen BOS, dan para pemeriksa lain nya apabila diperlukan. RKAS / RAPBS dibuat satu tahun pada awal tahun ajaran, dan perlu dilakukan revisi pada semester kedua.Sekolah dapat membuat RKAS / RAPBS tahunan yang dirinci tiap semester. Berdasarkan laporan rencana anggaran pendapatan dan belanja sekolah tahun 2016 di atas dapat dilihat bahwa jumlah rencana penerimaan bantuan operasional sekolah pada kantor pusat adalah sebesar Rp68.400.000,00 
Tabel 4.3

REALISASI PENGGUNAAN DANA OPERASIONAL SEKOLAH

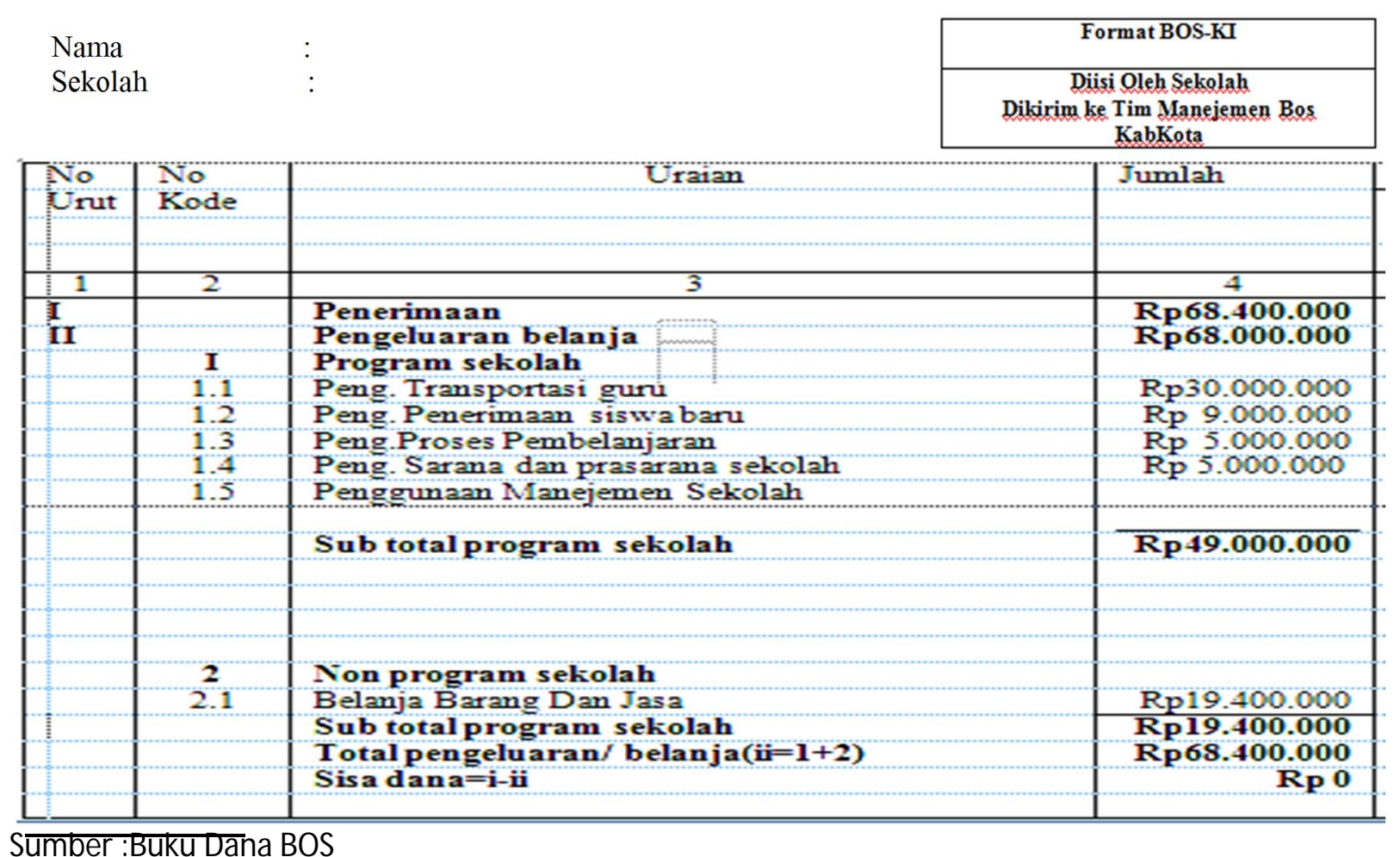

jumlah penerimaan sebesar Rp 68.400.000,00 dan jumlah ini pun sama dengan yang merupakan realisasi dana bantuan operasional sekolah dari BOS pusat senilai Rp68.400.000,00 yang digunakan untuk pengeluaran belanja penggunaan Transport guru 17 orang guru bulan juli,agustus,september di setiap bulan senilai Rp10.000.000,00 selama 3 bulan jadi jumlah keseluruhan senilai Rp30.000.000,00 penggunaan penerimaan siswa baru senilai Rp9.000.000,00 jumlah ini di peroleh dari jumlah penerimaan siswa baru senilai Rp4.000.000,00 dan Transport penerimaan siswa baru sebesar Rp5.000.000,00 proses pembelajaran bimbingan belajar guru senilai Rp5.000.000,00 jumlah ini diperoleh dari bimbingan belajar guru bulan agustus senilai Rp2.500.000,00 dan bulan september senilai Rp2.500.000,00 untuk non program sekolah belanja barang dan jasa sebesar Rp19.400.000,00 jumlah ini diperoleh dari pembelian barang dan jasa bulan juli senilai Rp8.324.000,00 bulan agustus Rp4.837.000,00 dan bulan September Rp6.239.000,00 
Tabel. 4.4

BUKU KAS UMUM

\begin{tabular}{|c|c|c|c|c|c|c|c|}
\hline •. & Tanplabelnetakn & No beit & Drain perequmus & 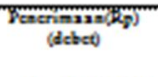 & 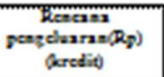 & 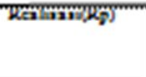 & 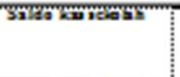 \\
\hline$\frac{1}{2}$ & 10,252016 & $\infty-1$ & 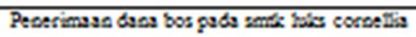 & 36.65.40000 & & & \$̣. $65 .+00.00$ \\
\hline$t^{2}$ & $\begin{array}{l}\text { JWh-reptamber } \\
2016\end{array}$ & $\infty-2$ & Peass, Trasupon gros & & K़. 300000000 & 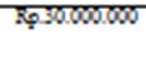 & R̦̣. 33.400000 \\
\hline s. & $\begin{array}{l}\text { Whireptember } \\
2016\end{array}$ & $\infty-3$ & Penge Proses pembelajaran & & Z़̧. 5.0000000 & క̣. 5.0000000 & Ŗ. 35.400 .000 \\
\hline 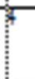 & $\begin{array}{l}\text { Jatreptember } \\
2016\end{array}$ & $\infty-4$ & Pengz Surass dos grasarasa & & ऱ̣. 5.000000 & Ṛ. 50000000 & 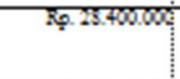 \\
\hline 5 & 75: 2016 & $\infty \cdot 5$ & Belagod Barang dos Jasa & & Ḅ़. 19.400000 & \$़̣. $19 .+00000$ & \$़̣. 9.0000 \\
\hline ริ & $\sin 2016$ & $\infty-6$ & 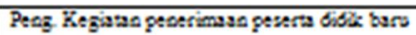 & & R̦. 90000000 & R. 9.000000 & Kp. \\
\hline
\end{tabular}

Sumber :Buku Dana BOS

Buku kas sekolah disusun berdasarkan perencanaan dana operasional sekolah dan realisasi penggunaan dana Bantuan Operasional Sekolah dari penerimaan maupun pengeluaran seperti dapat dilihat pada tabel 3.3 buku kas sekolah. Jumlah penerimaan dana operasional sekolah sebesar Rp. 68.400.000,00 yang digunakan untuk transportasi guru sebesar Rp. 30.000.000,00 jadi sisa dana Rp. 38.400.000,00,00 penggunaan proses pembelajaran Rp. 5.000.000,00 jadi sisa dana Rp. 33.400.000,00 penggunaan sarana dan prasarana Rp. 5.000.000 sisa dana Rp28.400.000,00 penggunaan belanja barang dan jasa Rp. 19.400.000,00 jadi, sisa saldo Rp. 9.000.000,00 pengunaan penerimaan peserta didik baru Rp. 9.000.000,00 maka, sisa saldo kas akhir sebesar Rp 0

\section{KESIMPULAN DAN SARAN 5.1 Kesimpulan}

Berdasarkan hasil penelitian dan pembahasan seperti yang telah di sampaikan pada Bab IV, maka dalam penelitian ini dapat disimpulkan sebagai berikut:

1. Pengelolaan dana BOS diantaranya meliputi perencanaan anggaran dana BOS, realisasi dana BOS dan disusun dalam buku kas sekolah. Perencanaam dana BOS disusun oleh kepala sekolah dan bendahara
2. Hambatan-hambatan lain yang sering muncul ketidaksesuian antara laporan dana BOS yang dibuat oleh Sekolah Menengah Teologi Kristen dengan buku petunjuk dana BOS.

\subsection{Saran}

Berdasarkan hasil penelitian, pembahasan dan kesimpulan yang telah dilakukan, maka peneliti mengemukakan saran sebagai berikut:

1. Dalam hal pelaporan penggunaan dana BOS, kepala sekolah, bendahara BOS dan guruguru hendaknya berkordinasi dengan baik, agar laporan penggunaan dana BOS dapat berjalan dengan lancar.

2. Ketersediaan pembukuan dana BOS kurang lengkap dan kurang teratur, sebaiknya semua pembukuan dana BOS disimpan secara lengkap dan ditata dengan teratur oleh bendahara BOS. Agar pembukuan dana BOS yang disusun dari perencanaan, realisasi dana BOS dapat sesuai dengan buku petunjuk dana bantuan operasional sekolah yang telah diatur dalam Undang Undang No 8 tahun 2017.

\section{Daftar Pustaka}

Buku Petunjuk Teknis Dana Bantuan Operasional Sekolah,2014.

Erich A. Helfert, D.B.A. 1997. Teknik Analisis Keuangan. Edisi 8, Erlangga. Jakarta 
Kamus Besar Bahasa Indonesia, Edisi Ke-3, Tahun 2007.

Kementerian Pendidikan Dan Kebudayaan, 2014, Buku Petunjuk Teknis Dana Bantuan Operasional Sekolah.

Mardiasmo, Prof. Dr. M.B.A., Akt. 2000. Akuntansi Keuangan Dasar. BPFE Jogjakarta Edisi 3, Fakultas Ekonomi Universitas Gadjah Mada.

Mardiasmo, Prof. Dr. M.B.A., Akt. 2000. Akuntansi Sektor Publik. BPFE Jogjakarta. Fakultas Ekonomi Universitas Gadjah Mada.

Rarmono D, Dr., M.Si., Ak., Ca Dan Sholihin M, Ph.D, Ak. Ca.(2015). Akuntansi Keuangan Daerah. Penerbit Upp Stim YKPN. Cetakan Pertama.

Peraturan Mendiknas Nomor 69 Tanun 2008, (2009,28 Oktober), “Tujuan Dan Sasaranprogram Bantuan Operasional Sekolah (Bos) ,"Http://Www .Simpatikemenag.Blogspot. Com/2016/04/ ,Id.Html Diakses 11 April 2017.

Siregar B. dan Siregar B, 2001, Akuntansi Pemerintahan Dengan Sistem Dana, Edisi3.

Supriyono (1999). Pengertian Biaya Dan Macam-Macam Biaya, Http://Kamarulintangsakti.Blogspot.In/201 4/03/.Html. Diunduh Pada 15 Maret 2017. 